\title{
A CONSTRUÇÃO AXIOLÓGICA E SUA APLICABILIDADE PARA O DIREITO DA PERSONALIDADE
}

\author{
AXIOLOGICAL CONSTRUCTION AND ITS \\ APPLICABILITY TO THE RIGHT OF PERSONALITY
}

\author{
CLEIDE APARECIDA GOMES ROdRIGUES FERMENTÁO ${ }^{1}$ \\ KARYTA MUNIZ DE PAIVA LESSA ${ }^{2}$
}

\section{RESUMO}

O presente artigo possui objetivo de analisar a construção histórica e epistemológica da filosofia dos valores - a axiologia, sua aplicabilidade no direito, em especial aos direitos da personalidade, e de que forma a humanidade se faz a fonte principal dos valores nos mais diversos tempos. Também se busca compreender de que forma os valores são caracterizados como instituídos e instituintes para o indivíduo e coletividade. Para buscar atender a estes problemas, utiliza-se a revisão bibliográfica como método, bem como pesquisa em leis, artigos, livros e dissertações, com objetivo de compreender qual entendimento sobre o tema em questão. Portanto, verifica-se que o direito, cuja finalidade última é a justiça, é gerado pelos valores, atuando nos direitos da personalidade que tutela os valores da essência humana, compreendido pela dignidade humana e também proteger a vida em sociedade com vistas à manutenção da harmonia social.

Palavras-chave: Axiologia. Direito da Personalidade. Filosofia. Valores Morais. Valores Sociais.

\section{ABSTRACT}

This article aims to analyze the historical and epistemological construction of the philosophy of values - axiology, its applicability in law, especially to the rights of the personality, and in what way humanity becomes the main source of values in the most diverse times. It also seeks to understand how values are characterized as instituted and instituting for the individual and collectivity. To seek to address these problems, bibliographic review is used as a method, as well as research on laws, articles, books and dissertations, to understand which understanding on the subject in question. Therefore, it appears that the law, whose ultimate purpose is justice, is generated by values, acting on the rights of the personality that protects the values of human essence, understood by human dignity and protecting life in society to maintaining the social harmony.

Keywords: Axiology. Moral Values. Personality Law. Philosophy. Social Values.

1 Doutora em Direito das relações sociais pela UFPR - UNIVERSIDADE FEDERAL DO PARANÁ; (2004) pós doutoranda em direito constitucional-hermeneutica jurídica pela UNISINOS-RS, Mestre em Direito civil pela UEM -Universidade Estadual de Maringá-Pr (2001) e graduada em Direito pela Universidade Estadual de Maringá (1977), Proprietária - Escritório de Advocacia Cleide Fermentão desde 1978; professora titular no Programa de Mestrado e Doutorado da UNICESUMAR - Centro Universitário de Maringá. cleidefermentao@gmail.com

2 Mestranda em Ciências Jurídicas pela UniCesumar (Bolsa CAPES/PROSUP), pós graduanda em Ciência Política pela UniCesumar, graduanda em Teologia pela Faculdade Teológica Sul Americana e graduada em Direito pela Faculdade Maringá (2015). karytamp@gmail.com 


\section{INTRODUÇÃO}

Desde os tempos remotos a história da evolução do homem e da sociedade tem reflexos no desenvolvimento dos valores. Estes corroboram com a construção da consciência humana. Os princípios proporcionam conceber não apenas a distinção entre o bem e o mal, mas também um método para a construção de um ideal almejado. Desta forma, os valores morais e sociais são basilares para o homem são basilares para ele, tanto nos costumes, na cultura, e estes nascem como resultados de crises que elevam a consciência humana.

Os valores surgem no interior de um grupo social, isso demonstra a importância e a relevância de compreender que o valor aceito pelo homem está relacionado ao valor social, onde o mesmo fixou as suas raízes. Os costumes de determinada sociedade estruturam os valores interiores do homem que nela vive, podendo ser entendido que dos valores morais e sociais se estruturam aos direitos personalíssimos da pessoa integrante em tal grupo social.

A axiologia, também chamada de filosofia dos valores, e o valor possui uma grande importância na seara jurídica. Em primeiro lugar, há de se atentar que o direito é um dos grandes norteadores da vida em sociedade, permeado e ligado com inúmeras outras áreas, como, a evolução da sociedade, a ética, a cultura, e os valores. É por meio da consciência humana valorativa que o homem entende o mundo em que vive. A apreciação axiológica administra a interpretação jurídica por meio da hermenêutica, e o propósito fulcral é a análise do valor. A conjuntura axiológica, como um dado cultural condicionador na circulação do direito, delineia a evolução histórica.

Os valores, podem ser considerados como propriedade do tecido das representações sociais, caracterizando-se como instituídos e instituintes da formação histórica do homem e da sociedade. Desta forma os valores são tidos como norte das opções de escolhas interligadas aos conhecimentos concebidos e também por meio de representações sociais, mas também possuem força que impulsiona os conhecimentos e reorganizam aqueles saberes provindos da experiência.

O direito não pode ser interpretado de forma única, para isso a importância da hermenêutica jurídica, e, o mesmo precisa ser aplicado, assim, para que haja a aplicabilidade coerente, é necessário a associação da interpretação do direito aos valores. Independente da época em que tal ato acontecerá, é sabido que um novo valor substituirá o anterior com a evolução social, gerando um novo direito.

Desta forma, vê-se que viver significa atribuir valor a vida e a construção cultural. Em outros termos os valores concebem ao homem e à sua consciência e fundamentos solidificados. É do valor que decorrerá seu comportamento, que se conhecerá seu caráter, suas ações diante das dificuldades, e dos mais distintos episódios da vida. E de antemão, antecipa-se que o direito da personalidade tutela os valores interiores da pessoa por representarem a sua essência.

Analisar-se-á a construção histórica e epistemológica da axiologia desde tempos remotos, sua formação filosófica desde Sócrates, a influência que a filosofia moderna sofreu da filosofia moderna, a contribuição de Kant e de tantos outros filósofos e juristas. Compreender-se-á de que forma o homem é considerado a fonte de todos os valores, quais formas 
estes podem justificar as ações humanas e como os valores morais e sociais que fundamental o direito e o convívio social, podem contribuir para a própria valoração e ideias humanas.

A presente pesquisa parte dos seguintes questionamentos: existe relação entre a filosofia dos valores e a formação do direito? E especificadamente com o direito da personalidade? Como os valores morais e sociais podem contribuir para a formação e tutela dos direitos da personalidade?

Para responder estas questões, optar-se-á pelo método dedutivo e hipotético-dedutivo, para alcançar-se-á um referencial teórico válido e relevante, com o auxílio de estudo qualitativo, por meio de coleta de bibliografias, doutrinas e leis - Constituição Federal, Lei de Diretrizes e Bases da Educação Nacional, Projeto Nacional de Educação - a partir de consultas na internet, acervo da Biblioteca da Universidade UniCesumar e Google Scholar sobre o assunto em questão: axiologia, direitos da personalidade, dignidade humana, valores morais e sociais.

\section{A AXIOLOGIA: VISÃO HISTÓRICA-EPISTEMOLÓGICA}

O estudo sobre valores teve sua gênese, aproximadamente em 400a.C, com Sócrates, corroborando com o período áureo da Filosofia, tornando-se um dos pais da Filosofia. A axiologia é tão antiga quanto à existência humana. Na Antiguidade Clássica os gregos entendiam que axios poderiaia ser explicado por aquilo que tem valor, aquilo que possui dignidade para ser estimado, mas nunca mensurado. Assumindo, pois, a importância do valor na história.

Com o intuito de entender sobre os valores humanos desde seu nascimento até o momento onde se vê o processo sócio histórico mais desenvolvido, é necessário captar sobre a constituição do que entendia-se sobre o homem grego, uma vez que a civilização grega era considerada, tanto, de suma importância no que tange o meio da educação, mas também "[...] não é só o espelho onde reflete o mundo moderno na sua dimensão cultural e histórica ou um símbolo da sua autoconsciência racional" (JAEGER, 2013, p. 7).

Sócrates combateu veementemente o relativismo e o subjetivismo dos sofistas, defendendo a objetividade e o absolutismo dos valores éticos. Seguido posteriormente por Platão, e também Aristóteles; Sócrates entendia que o conflito ao relativismo e subjetivismo, a luta pela objetividade e a absolutidade dos valores éticos era a fórmula de sua diligência.

A valoração do homem ganha uma nova roupagem com a história grega. A moral tradicional da época acabou sofrendo ameaças por conta da racionalização oriunda dos ensinamentos dos sofistas. Estes acabaram não se importando para gênese do universo, mas voltava para os valores morais e políticos (PLATÃO, 2002), levando ao surgimento da relativização dos valores. Platão ao demonstrar sobre o mundo de padrões metafísicos, faz apontamento sobre os valores morais, e em sua obra "A República" acredita que a divisão racional do trabalho é uma forma correta dede a organização da cidade ideal e por isso foi visto como um reformador social (PLATÃO, 2002).

Platão construiu a teoria das ideias - o núcleo central da sua filosofia - onde em síntese, a ideia de valores é maximizada pela concepção de bem, como do valor ético e também 
do valor estético; não podendo olvidar que este guiou-se pela metafísica. (PLATÃO, 2002). Já em Aristóteles, há prosseguimento para o viés da ideia de bem nas coisas e na realidade empírica, onde o valioso adquire abundante caráter cósmico.

A felicidade em Aristóteles (1999), não era proveniente de obter prazer - seja de qual fonte vier - mas esta seria encontrada pela razão, ou seja, a pessoa que alcança maior desenvolvimento da razão contemplará a felicidade por meio das virtudes, sendo estas uma excelência moral e de um "estado intermediário, porque nas várias formas de deficiência moral há falta ou excesso do que é conveniente tanto nas emoções quanto nas ações, enquanto a excelência moral encontra e prefere o meio termo (ARISTÓTELES, 1999, p. 42), desta forma para este filósofo, os valores humanos estão relacionados com o que entende sobre o ideal de bem que submete o homem ao encontro da felicidade.

A Filosofia Clássica muito influenciou a formação da Filosofia Moderna, e esta teve papel fundante e essencial na composição da filosofia dos valores. Dentro deste período, não se pode deixar de mencionar Immanuel Kant. Ele confrontou categoricamente a ética clássica que vinha por anos influenciando aquele período, inaugurando uma filosofia crítica e totalmente oposta ao dogmatismo (KANT, 1980).

Com uma distinção básica entre ser e dever ser, Kant ofereceu uma nova perspectiva ao valor. Esta busca por uma construção filosófica livre de bagagens de seus antepassados, é entendido como o cerne de sempre questionar sobre as suas próprias faculdades da razão, seguida pelas possíveis possibilidades de um conhecimento, seguida pelos seus limites, foi inclusive com esta indagação que ocorreu a revolução copernicana na Filosofia (BAMBIRRA, 2008, p. 4905).

Embora Kant não tenha desenvolvido propriamente dito, uma axiologia, em sua elaboração de uma deontologia - 'teoria dos deveres', ocorre uma transferência da ideia de valor para o domínio da consciência pessoal, "neste mundo, e até fora dele, nada é possível pensar que possa ser considerado como bom sem limitação a não ser uma só coisa: uma boa vontade. " (KANT, 1980, p. 109), também explicado por Hessen que "a consciência moral torna-se verdadeira pátria dos valores éticos. " (HESSEN p. 26, 1980).

Foi a partir de meados do século XIX que o rigor científico sofreu uma busca maior ao valor. Com as importantes contribuições pioneiras do filósofo e lógico Lotze em relação aos estudos axiológicos, passou a ser considerado como o verdadeiro pai da moderna filosofia dos valores, principiando sobre o tema em seu livro Mikrokosmos, onde distingue "ser" e "valor", ou seja, o "mundo dos valores" é diverso do "mundo dos entes" (HAUBERT, 2018).

Em suma, o valor poderia ser compreendido a partir do domínio espiritual, bem como pode ser compreendido por meio da inteligência (HESSEN, 1980, p. 26-27). Juntamente com esta ideia, também conceitua o valor e o valer, onde aquele sempre será algo livre da realidade.

Já no aspecto da moderna filosofia dos valores, Franz Brentano, em sua obra A Origem do Conhecimento Moral (1889) traz contribuição relevante reconhecendo a natureza do valor como de um phaenomenon sui generis - ou seja - fenômeno de gênero próprio, singular. Para ele, das três classes fundamentais de fenômenos psíquicos "entre as referências intencionais, retomando o tema tratado nas Meditações cartesianas, mas até então ignorado" (BAMBIRRA, 2008, p. 4907) 
A primeira classe é constituída pelas representações, que podem ser intuitivas ou obtidas pelos sentidos; a segunda classe é a dos juízos, que provocam ininterruptamente um representar, porém, nem sempre associando uma representação a outra; a terceira classe é a das emoções. A noção de bom compreende-se aquilo que é considerado verdadeiro, só é justo ao admitir tal referência. Já em relação a algo que é tido como bom, só será assim entendido ao consistir de amá-lo e então será justo. Em outras palavras aquilo que se ama com amor justo, sendo este, justo de ser amado, é literalmente o bom (BRENTANO, 2002).

Ao contrário do que se vê a partir da análise de objetos, onde são sempre imutáveis, Johannes Hessen entende que há a perenidade dos valores, estes não se alteram com a modificação dos objetos em que se manifestam. Assim sendo, aporta a teoria de que os valores, por exemplo, os estéticos do belo, do sublime, do gracioso, etc., conservaram mesmo ao serem esfacelados todos os objetos de arte. Ao entendimento de valores, Scheller acrescenta os aludidos éticos para os pessoais e os das coisas para os impessoais (PEREIRA, 2000). Para além dessas correntes, no século XX o termo valor começou a ser distinguido das noções de bem e de ser para assumir um sentido derivado de atividades puramente humanas, resultando na configuração de uma reconhecida teoria de valores.

A teoria de valores foi reconhecida após inúmeras correntes somarem com conceituações particulares, e, no século XX o termo com sua significação passou a ser diferenciado do que se entendia como bem e como ser, e evidenciou-se no tocante ao humano. Miguel Reale, transfere o verbo ao substantivo valer, trazendo a pura revelação do valor, de forma epistemológica própria, entendendo que o homem obtém conhecimento e consciência do valor nas mais diferentes modalidades como do ponto de vista histórico, militar, artístico e econômico (REALE, 1982). Percebe-se que há um plurívoco entendimento de valor e, portanto, vale se atentar que valor não é apenas questão de preferência, mas sim do que é preferível e desejável, porém, valor não se trata apenas de um ideal, mas sim uma norma das preferências, ou o que se entende de critério de juízo.

Valor pode ser considerado como uma possibilidade de escolha, assim, a teoria do valor inclina-se a valer de possibilidades declaradas de escolhas (ABBAGNANO, 2007, p. 993) e que "aquele que nega todos os valores, nada mais vendo neles do que ilusão, não poderá deixar de falhar na vida. Aquele que tiver uma errada concepção dos valores não conseguirá imprimir à vida o seu verdadeiro e justo sentido. " (HESSEN, p. 23, 1980).

Os fundamentos gerais e superficiais sobre o valor podem até parecer fáceis, todavia, quando se trata da sua teorização ocorre um embate. Lotze (apud HAUBERT, 2018) e Miguel Reale (1982) defendem que assim como ser é o que se é, então valor é o que vale, enquanto Nader (2019) compreende que a conceituação de ser e de valor são irredutíveis.

De acordo com Lucília Bastos, a filosofia dos valores é considerado um estudo relativamente novo, mas com algumas correntes principais que valem ser destacadas: o psicologismo axiológico compõe a primeira, destaca que os valores podem ser levados pelo relativismo e subjetivismo, afinal conforme a vivência, os valores podem ser experimentados; a segunda é composta pelo cosmologismo, onde o valor é tido como uma determinação unicamente do ser; já a terceira corrente é composta pelo Neokantismo, o que possui valor ou validade é inserido aqui, na qual a ordem real do ser distingue-se da ordem ideal, e passa a constituir uma esfera de coisas que valem; e para finalizar, o ontologismo preenche a quarta corrente, tido como a coisificação dos valores, ou seja, valores não determinam o modo de 
ser de alguém, mas de entes em si (BASTOS, 2006, p. 215-6). De fato, não se pode harmonizar as mais variadas correntes, por isso nada mais importante do que um exame mais profundo sobre tais questões.

Uma questão crucial quanto aos valores é em relação à sua subjetividade e relativismo ou ao seu objetivismo e absolutismo. De um lado se tem o relativismo dos valores que compreende como ponto fundante que todo o valor e valoração condiz com a presunção de uma relação com um sujeito valorante. 0 subjetivismo axiológico, tem como alguns de seus representantes Ortega y Gasset, Meinong, Christian von Ehrenfels, e defendem que "a tese de que os valores não têm validade por si, visto que o sujeito atribui significado às coisas de acordo com a reação positiva ou negativa que Ihe provocam" (NADER, 2019, s/p).

Do outro lado, se tem o caráter absoluto dos valores, o qual diz sobre aqueles que possuem eficácia em si mesmo seja para qual for o espírito. Pode-se listar alguns autores importantes que defendem a dimensão absoluta dos valores entendendo que "a existência dos valores independe do sujeito, pois prescindem de estimativa ou conhecimento. Os valores teriam existência em si e por si" (NADER, 2019, s/p), como Max Scheler, Nicolai Hartamann, Joahnnes Hessen.

A axiologia é importante para a filosofia e muito nobre a ela, afinal, apenas por meio daquela que há possibilidades de alcançar terreno sólido para uma renovação da cultura ou quem sabe a elaboração de uma nova cultura com dimensões cada vez mais solidárias (MONDIN, p. 159, 1980). O valor não é um ser em si, muito menos um querer bom ou mau, porém é algo que vem e se institui na subjetividade na relação do ser com as coisas ou mundo, ou consigo mesmo, ou ainda na sociedade em que está inserido, uma vez que "o homem é a fonte de todos os valores porque é inerente é sua essência valorar, criticar, julgar tudo aquilo que lhe é apresentado, seja no plano da ação ou no do conhecimento. " (REALE, 2000).

\section{VALORES MORAIS E SOCIAIS}

Os valores justificam as ações, e possuem uma profundidade em si, e, para sua realização é admitido inúmeros graus - como exemplo, se tem o "heroísmo da renúncia e o sacrifício de si mesmo, valem eticamente mais que uma simples e pequena transformação moral" (HESSEN, p.60-61, 1980).

Para Miguel Reale não seria correto dizer que valores sejam apenas fatores éticos, servindo para ilustrar acerca da vivência humana, contudo também se trata de elementos constitutivos dessas vivências, o que ele chama de historicismo axiológico. Os quais o ser humano cumpre em sua vivência particular, que vai portando demonstrações por meio do tempo, podendo ser, tanto exemplares como diversas (REALE, p. 201, 2002). Também cumpre dizer que os valores não portam essência ontológica em si, todavia são manifestados nas coisas que possuem valor.

Não se tratando de influência empírica, isolada ou quem sabe individual, mas sim do todo, na universalidade, "como consciência histórica, no processo dialógico da história que 
traduz a interação das consciências individuais, em um todo de superações sucessivas " (REALE, p.201, 2002). Cumpre ressaltar, portanto que apenas o homem, dentre todos os seres, é capaz de valores, ou seja, é no ser humano que se acha o valor fundante, intrínseco a ele, que vale por si só.

O homem ao subjugar a terra, formou o mundo da cultura o que se pode dizer à sua imagem e semelhança (REALE, 2002, p. 209), portanto ser é o seu dever ser. A problemática dos valores tem mais a ver com a dificuldade de sua compreensão, ou seja, o impedimento de percepção e não de sua elucidação. Assim tudo que se tem sobre bem cultural só é enquanto deve ser, o que Reale chama de "intencionalidade da consciência" (REALE, 2002, p. 209), a qual se protege como uma constante axiológica fundamental. Em outras palavras, a emissão de um juízo de valor é entendida quando o homem realiza atos durante toda a sua vida, pois é de sua própria essência estar sempre valorando.

Isto também pode ser relacionado ao fato de desejar algo, e assim se faz porque algo parece valoroso. Desta forma falar em valorar quer dizer a tudo aquilo que de alguma forma enriquece o ser humano, e, algo possuirá valor quando for apropriada para suprir determinadas necessidades (PAUPÉRIO, 1992). É o exemplo de valor moral, que possivelmente sempre satisfará possíveis necessidades e também exigências morais.

Quando se fala em valores da pessoa, estes podem se desdobrar em inúmeros outros valores, podendo ser dispostos em morais e sociais, e os direitos da personalidade são valores imprescindíveis para a pessoa humana, uma vez que é o direito tido como instrumento possibilitador para a realização dos valores nos momentos da vida social.

Os valores morais advêm da palavra "mores" que corresponde a costumes. A moral pode ser compreendida como normas implícitas em códigos e leis, todavia estão ali contidas regulamentando a ação do homem na sociedade. É comum a palavra moral ser comparada à palavra ética, todavia adiante será mostrado que hodiernamente cada uma tem sua aplicabilidade específica. Para Vázquez (1984), a moral deriva da necessidade coletiva que os homens possuem de relacionarem entre si, todavia, zelando pelo bem de todos, é aquela mescla de regras e normas cujo intuito é regular as interações sociais, não esquecendo a probabilidade de mutação conforme a evolução política e econômica.

É imprescindível pensá-las de forma mutável e flexível. "A Ética é uma ciência da moral, pois questiona ao buscar o porquê e em quais condições determinada ação é considerada boa ou má, até que ponto ajuda a construir a identidade de uma nação, grupo ou pessoa" (RIBEIRO, 2000, p. 137). Para Miguel Reale (2002, p. 42) "a teoria do mínimo ético consiste em dizer que o Direito representa apenas o mínimo de Moral declarado obrigatório para que a sociedade possa sobreviver".

Em relação aos valores morais, o posicionamento de Kelsen reflete que o direito é uma ciência desvinculada de qualquer valor, uma ciência jurídica que para ele é uma realidade autônoma e, portanto, ao se realizar uma análise, deve ser distinguido de quaisquer juízos (KELSEN, 1999, p.45). Para o filósofo, a dedicação deve unicamente ser à norma. Havendo um direito moralmente bom e um direito moralmente mau, somente assim é que haverá a justificativa seguida por tal contraposição do Direito positivo pela Moral, todavia há se atentar que esta ideia não encontra mais égide como afirma Paupério (1992, p. 103), já que "a objetividade e a neutralidade axiológica constituem em si valores. E como a neutralidade 
axiológica é em si mesma um valor, a exigência de uma total ausência de valores, de uma completa neutralidade valorativa é paradoxal".

O direito positivo em sua normatividade pura não possui força para gerar uma obrigação, mas esta é gerada porque contém valor, ou seja, ocorre a obrigação exatamente por que a norma é vista como legítima e justa (VASCONCELOS, 2006). Ronald Dworkin (2010) compreende que os princípios, com aspectos morais e os integra ao sistema jurídico, já Habermas (1997) afirma que "a teoria dworkiana apoia-se na premissa segundo a qual há pontos de vista morais relevantes na jurisprudência, porque o direito positivo assimilou inevitavelmente conteúdos morais".

De uma forma ou de outra, adota-se nesta pesquisa que os valores morais e sociais estão contidos no direito e também no convívio social, conforme dito anteriormente, é de suma importância inclusive para a evolução das próprias ideias humanas, sendo que a "essência de qualquer sociedade é a reunião moral dos homens ordenada ao bem comum (...)" e que para alcançar este bem comum é "preciso que os interesses privados se subordinam aos interesses supremos da comunidade". (PAUPÉRIO, 1992, p.45).

\section{A IMPORTÂNCIA DOS VALORES PARA OS DIREITOS DA PERSONALIDADE}

É da essência do próprio ser humano conhecer e querer, mas também lhe é intrínseco o ato de valorar. Valora-se tudo, e não é possível viver a vida sem proferir constantemente juízos de valor (HESSEN p. 40, 1980). Para Reale, a escolha de algo e consequentemente a existência de um sentido só é possível por conta do valor, é por meio deste que aqueles são acarretados (REALE, p.186, 2002). É certo dizer que apenas o homem é passível de valores e por esta razão que a axiologia é válida, sendo que viver - em outras palavras - é escolher seu posicionamento diante de valores, aplicando em sua vida à medida que estes vão engrandecendo a personalidade pessoal ao dar valor ao que se tem ao redor, como aos objetos, aos outros seres humanos e também ao seu próprio eu.

Um exemplo prático sobre a formação de valores trazida por Vásquez (2008) está em torno da prata, que inicialmente ela é uma propriedade física, natural e sensível, ou seja, um objeto natural, e com o passar do tempo, em decorrência das necessidades produzidas passar a possuir outras qualidades, as necessidades são sócio historicamente, e o valor que passa a ter para o homem se altera conforme sua existência social, histórica e cultural.

Diante disto, "os princípios de identidade e de não-contradição governam, como princípios universais, toda ciência e todas as possibilidades de conhecimento. " (REALE, p.59, 2002) e, com o universo jurídico não poderia ser diferente. 0 direito também é detentor de princípios, afinal não é provável que haja ciência não fundamentada em pressupostos, ou seja, uma vez que princípios se caracterizam em verdades, estes juízos fundantes são a base para um emaranhado de juízos. Reale traz o exemplo de um edifício, com suas vigas mestras, as quais são o ponto de referência. Então, quando se tratar de qualquer ciência, esta também terá suas colunas mestras, que lhe conduzirá a um apoio lógico, o que se chama de princí- 
pios, para uns, para determinados fins, e para outros, para outras finalidades, todavia, servem de apoio na estrutura geral do conhecimento humano (REALE, p.61, 2002).

Viver sempre implicará em valorar (NADER, 2019). O homem considerando o mundo por meio de perspectivas valorativas incidirá no direito, efeito da cultura humana, indubitavelmente congruente com os valores. Portanto, os valores são fundantes para a formação do Direto e este é consequência de uma polaridade, uma vez que se concretizando elementos axiológicos, satisfazendo ou não as propensões humanas, logrando ou não triunfo, a intenção é de estar sendo concretizados os valores positivos (NADER, p. 52, 2019). Em outras palavras, vale lembrar que os valores são a essência do Direito, contidos nos sistemas jurídicos por meio de normas. No entendimento de Norberto Bobbio "a filosofia do direito pode, consequentemente, ser definida como o estudo do direito do ponto de vista de um determinado valor, com base no qual se julga o direito passado e se procura influir no direito vigente" (BOBBIO, 1995, p. 138).

A essência do direito é formada pelos valores (NADER, 2019). Os valores geram o Direito, e este tem como objetivo proteger a vida em sociedade, levando-a a uma harmonia social. Assim, é imprescindível estudar os valores, pois as normas são a efetivação do valor (FERMENTÃO, p.623, 2011). Os valores humanos atuam na dignidade humana e na ética da pessoa e neste ínterim são os direitos da personalidade que tutelam aquilo que se entendem sobre os valores da essência humana: sua dignidade. 0 direito, além de efetivar valores, também estabelece acerca deles, ou seja, o direito tem como um dos seus componentes o valor.

O homem sempre estará concedendo valor a tudo a seu redor, sendo que viver sempre preiteará "ato de criação de meios que viabilizem a existência; a criatividade é seletiva, discriminadora, pois o homem procura desvencilhar-se do que lhe parece o mal e realizar o que Ihe parece o bem" (NADER, 2019, s/p) e a ação humana, enquanto objeto cultural gera o valor, desta forma, o direito sempre terá um juízo de valor ao disciplinar as ações humanas e seus relacionamentos, para tal, é necessário uma base ética.

Nem todos os valores derivam da ética, com base em seus princípios morais, como por exemplo, os direitos à saúde, à cultura, aos esportes (NADER, 2019, s/p). Todavia, em sua grande maioria, com intuito de zelar pela integridade da formação da sociedade, os juízos de valor sempre estarão nas futuras realidades jurídicas almejando o justo. Como por exemplo, o direito à vida, à liberdade, o patrimônio são direitos essenciais à humanidade, então quando o direito projeta valores, sempre ansiará pela tutela da dignidade do homem.

Se só é possível conhecer o homem quando se conhece os valores que regem sua vida (HESSEN, 1967), também pode-se compreender o direito, analisando quais os fins que suas normas pretendem atingir. Regular a conduta humana, para o direito, também é tida como uma execução do ethos, ou seja, produto da cultura (SALGADO, 2006), nesse mesmo sentido Paupério, (1992, p.47) também compreende que "o direito é obra cultural e, portanto, visa também, como a ética, à criação de valores".

No que tange ao direito de personalidade, este pode ser compreendido como direito inato da pessoa humana, intrínseca da mesma, ou seja, é considerado o primeiro bem da pessoa, como afirma Elimar Szaniawski:

Sob a denominação de direitos de personalidade, compreendem-se os direitos personalíssimos e os direitos essenciais ao desenvolvimento da pessoa humana que a doutrina moderna preconiza e disciplina no corpo do CC 
como direitos absolutos, desprovidos, porém, da faculdade de disposição. Destinam-se a resguardar a eminente dignidade da pessoa humana, preservando-a dos atentados que pode sofrer por parte de outros indivíduos. (SZANIAWSKI, 2005, p.71)

Helmut Coing compreende o princípio da dignidade da pessoa humana de acordo com duas concepções: no primeiro momento imputa-se que a proteção da pessoa humana no que tange à sua integridade, ou seja, serve de impedimento contra práticas ou ofensas físicas e psíquicas contra o ser humano, protegendo de forma geral a sua vida; em segundo momento diz respeito à expressão do direito do ser humano ser respeitado como ser intelectual, que representa então a garantia do direito à autodeterminação, ir e vir, escolher onde viver, etc. (SZANIAWSKI, 2005, p.140).

A dignidade da pessoa humana é o primeiro e último fundamento da pessoa humana que guarda na vida e na morte os direitos individuais, uma vez que além de ser considerado um supra princípio, também é o mais importante de todo sistema. Com a promulgação da Constituição Federal de 1988, inúmeros valores e princípios foram instaurados o que trouxe um novo tempo para uma nova ordem jurídica (MOARES, p.233, 2006), a dignidade da pessoa humana foi eleita como fundamento do próprio Estado Democrático de Direito. A tutela integral e primordial da pessoa trouxe alteração paradigmática, possuindo valor constitucional, sendo princípio fundamental e tido como elos de todo o sistema (CANTALI, 2009, p.86).

Segundo Kant, "no reino dos fins tudo tem um preço ou uma dignidade" ou "quando uma coisa tem um preço, pode-se pôr em vez dela qualquer outra como equivalente; mas quando uma coisa está acima de todo preço, e, portanto, não permite equivalente, então tem ela dignidade" (KANT, 1986, p. 77).

É possível considerar inúmeras dimensões sobre a dignidade como: ontológica, comunitária ou social, histórico-cultural, e também a negativa e prestacional. A primeira, quer dizer que a dignidade é algo inerente ao ser humano, a segunda é que todas as pessoas são iguais em dignidade e direito, a terceira, ele entende sendo inequívoca, uma vez que o conceito está sempre em um processo de construção em si, e também para responder às necessidades sociais, e por fim, leva-se em consideração que a dignidade pode ser manifesta ao mesmo tempo com o que se chama de autonomia da pessoa, ou em outras palavras, o que se entende de direito de autodeterminação para tomada de decisões que é própria à pessoa (SARLET, 2007, p.30-33).

O direito geral da personalidade resguarda o homem em toda e qualquer circunstância, levando em consideração que a proteção de tal tutela tem como objetivo de preservar, em todas as situações, a dignidade da pessoa humana (PERLINGIERI, 1972, p.186). Com a valorização da pessoa humana, percebe-se que a conceituação de personalidade sofreu mudanças, não apenas em relação a sua capacidade de ser sujeito de direitos, ou seja, a personalidade deve ser considerada como uma expressão intrínseca e da própria pessoa, ou seja, consequentemente relacionada à pessoa, logo também ao valor.

O direito é um valor e permanece no que se chama de estado do imaginário até que a norma jurídica o incorpore, trazendo à tona sua vigência e efetividade (FERMENTÃO, 2011, p.624), na relação entre o valor e o direito, tem-se uma intimidade que visualiza facilmente pela perspectiva ontológica, e sempre que valores surgem, o direito é enriquecido. Este é composto por finalidades, tradições, significados, valores, etc. Ambos nascem principiam 
do corpo social e só assim fazem quando são instigados por inevitabilidade exposta. Importante atentar que "se os valores se apoiam no consenso são mutáveis de acordo com o grupo social, o tempo e o espaço" (FERMENTÃO, 2011, p. 624).

É no decorrer do tempo que os direitos vão surgindo baseado nos valores, garantindo-os e protegendo-os. No tocante aos direitos da personalidade não é diferente. Os valores que compreendem a personalidade humana são tutelados pelo direito da personalidade, igualmente a quaisquer outras privações humanas. 0 valor humano é inerente ao homem, intrínseco a ele, portanto para estruturar moralmente e eticamente, surge o valor do direito, seguido do valor justiça, cujo âmago é a igualdade. A finalidade última é a justiça, sendo que a base da ordem jurídico normativa é o valor e o direito é o meio da justiça (FERMENTÃO, 2011, p. 625).

\section{CONSIDERAÇÓES FINAIS}

Com o objetivo de elucidar uma revisão teórica de estudos que versam sobre a filosofia dos valores - axiologia - e empreender uma análise crítico reflexiva dos textos levantados, realizou-se uma verificação bibliográfica que perfez na composição de uma condensação histórico epistemológica da axiologia, demonstrando convicções de estudos axiológicos desenvolvidos nos últimos anos, na seara da filosofia dos valores.

Todos os seres humanos, em sua individualidade de ser e pensar, possuem valores, e estes principiam suas ações como bússola, tornando tais atitudes e desenvolvimento, um reflexo do que tem sido norteado. A ação humana precisará, portanto, se adequar ao agir dos outros membros da sociedade. Portanto, quando se tratou de valores morais e sociais, entendeu-se que passaram a ser comuns entre todos, ou seja, a adoção desta forma comum é uma premissa axiológica que conclui a percepção da existência da vida humana no mundo.

Os valores surgem no interior de um grupo social, o valor aceito pelo homem está relacionado ao valor social, onde o mesmo fixou as suas raízes. Os costumes de determinada sociedade estruturam os valores interiores do homem que nela vive, podendo ser entendido que dos valores morais e sociais se estruturam aos direitos personalíssimos da pessoa integrante em tal grupo social.

Os valores são considerados como propriedade das representações sociais, caracterizando-se como instituídos e instituintes da formação histórica do homem e da sociedade. Desta forma os valores são tidos como norte das opções de escolhas interligadas aos conhecimentos concebidos e também por meio de representações sociais, mas também possuem força que impulsiona os conhecimentos e reorganizam aqueles saberes provindos da experiência.

A teoria de valores foi reconhecida após inúmeras correntes somarem com conceituações particulares, e, no século XX o termo com sua significação passou a ser diferenciado do que se entendia como bem e como ser, e evidenciou-se no tocante ao humano

Os valores moldam tudo que há de ações em sociedade e basilares para o convívio social do homem, portanto viu-se que os valores tratam de elementos culturais, previamente 
criados e desenvolvidos pelos povos para que haja uma qualidade de vida e esta seja alcançada, dentre estas maior justiça, maior paz, maior acesso a direitos sociais. Diante disso, percebeu-se que não há dúvidas de que os valores, se tratam de fundamentos sociais e culturais, e são flexíveis, passíveis de alteração conforme as próprias mudanças e avanços da sociedade. As gerações são atualizadas, são transformadas, são modernizadas e com isso, não se pode olvidar de que sempre estarão procurando alterações para adotar melhores métodos de vida. Os princípios se caracterizam em verdades e juízos fundantes são a base para um emaranhado de juízos.

Uma questão crucial quanto aos valores é em relação à sua subjetividade e relativismo ou ao seu objetivismo e absolutismo. De um lado se tem o relativismo dos valores que compreende como ponto fundante que todo o valor e valoração condiz com a presunção de uma relação com um sujeito valorante. Do outro lado, se tem o caráter absoluto dos valores, o qual diz sobre aqueles que possuem eficácia em si mesmo seja para qual for o espírito.

O homem considerando o mundo por meio de perspectivas valorativas incidirá no direito, efeito da cultura humana, indubitavelmente congruente com os valores. Portanto, os valores são fundantes para a formação do Direto e este é consequência de uma polaridade, uma vez que se concretizando elementos axiológicos, satisfazendo ou não as propensões humanas, logrando ou não triunfo, a intenção é de estar sendo concretizados os valores positivos.

O direito de personalidade é um direito fundamental, enquanto que o princípio da dignidade da pessoa humana é uma cláusula geral de proteção da personalidade no Brasil. A conceituação da dignidade é multidisciplinar, originário, derivado, inderrogável, tanto que é muito comum de ser confundido com o conceito de personalidade, é tida como um princípio matriz, gerador de outros direitos fundamentais.

O presente artigo que delineou, cronologicamente, a evolução e o amadurecimento da concepção sobre o conceito de valor, e principalmente a sua aceitação dentro do universo jurídico, tem-se a noção de que o Direito não se interpreta por si só, e, para que seja aplicado, deve ser interpretado e que o ser humano é pessoa e, como tal, possui capacidade e personalidade, considerando que a capacidade de agir é que dá à pessoa personalidade, o que o distingue. Por meio da personalidade, o homem torna-se responsável pelas obrigações e, por meio da liberdade, alcança o "status" de ser humano e, como tal, tem o direito à sua dignidade, como direito de personalidade tutelado pelo Estado. Para que isto ocorra, é indispensável subjuga-los a valores.

\section{REFERÊNCIAS}

ABBAgnANO, N. Dicionário de filosofia. 5. ed. São Paulo: M. Fontes, 2007.

ARISTÓTELES. Aristóteles: vida e obra. Trad: Editora Nova Cultura. São Paulo: Nova Cultura, 1999.

BAMBIRRA, Felipe Magalhães. Legados da Antiguidade ao Direito eà moderna Filosofia dos Valores. Revista do CAAP. Afonso Pena, MG, p. 7-52, 2008. Disponível em: https://webcache.googleusercontent.com/search?q=cache:CW OXMJb7CkoJ:https://revistadocaap.direito.ufmg.br/index.php/revista/article/download/1 1/10+\&cd=4\&hl=pt-PT\&ct=clnk\&gl=br. Acesso em: 15 dez 2019. 
BASTOS, Lucília Izabel Candini. Valores, princípios e regras. Revista Jurídica do Uniaraxá, Araxá (MG), v. 10, n. 9, p. 211-227, 2006.

BRENTANO, F. Psychology from an empirical standpoint. London: Routledge, 1995.

BRENTANO, F. El origen del conocimiento moral. Trad. Manuel Garcia Morente. Madrid: Tecnos, 2002.

BOBBIO, Norberto. A teoria do ordenamento jurídico. In: O positivismo jurídico: lições de filosofia do direito. São Paulo: Editora Ícone, 1995.

BOBBIO, Norberto. Positivismo Jurídico. Lições da filosofia do direito. 1.ed. São Paulo: Ícone Editora. 2017.

BRENTANO, F. Psychology from an empirical standpoint. London: Routledge, 2002.

CANTALI, Fernanda Borghetti. Direitos da personalidade: disponibilidade relativa, autonomia privada e dignidade humana. Porto Alegre: Livraria do Advogado, 2009.

DWORKIN, Ronald. Levando os direitos a sério. Trad: Nelson Boeira. 3. ed. São Paulo: WMF Martins Fontes, 2010.

HAUBERT, Laura Elizia. Hermann Lotze: observações sobre o conceito de linguagem na obra 'Microcosmus'. Guairacá Revista de Filosofia, Guarapuava, PR, v. 34, n. 1, p. 60-88, 2018.

HESSEN, Johannes. Filosofia dos valores. Trad. L. Cabral de Moncada. 5.ed. Coimbra: Armeni Armada, 1980. Coimbra: Armênio Amado, 1980.

FERMENTÃO; SILVA. A tutela dos valores interiores e da consciência humana pelo direito da personalidade. Revista Jurídica Cesumar. Maringá, PR, v.11, n. 2, p. 615-632, 2011. Disponível em: https://periodicos.unicesumar. edu.br/index.php/revjuridica/article/view/2078. Acesso em: 13 jul 2019.

HABERMAS, Jürgen. Direito e democracia entre facticidade e validade. Trad. Flávio Beno Siebeneichler. Rio de Janeiro: Tempo Brasileiro, 1997.

JAEGER, W. Paideia: a formação do homem grego. 5. ed. São Paulo: Martins Fontes, 2013.

JODELET, D. Experiência e representações sociais. In MENIN, Maria Suzana De S.; SHIMIZU, A. de M. Experiência e Representação Social: questões teóricas e metodológicas. São Paulo: Casa do Psicólogo, 2005.

KANT, Imannuel. Fundamentação da Metafísica dos Costumes. Trad: Paulo Quintela. Lisboa: Ed.70, 1980.

KELSEN, Hans. Teoria Pura do Direito. Tradução: João Baptista Machado. 6. ed. São Paulo: Martins Fontes, 1999.

MORAES, Maria Celina Bodin de. A constitucionalização do direito civil e seus efeitos sobre a responsabilidade civil. Revista Direito, Estado e Sociedade, Rio de Janeiro, RJ, v. 9, n. 29, p 233-258, 2006. Disponível em: https:// revistades.jur.puc-rio.br/index.php/revistades/article/view/295/267 Acesso em: 30 out 2019.

MONDIN, Battista. Introdução à Filosofia: Problemas, Sistemas, Autores, Obras. São Paulo: Editora Paulus, 1980.

NADER, Paulo. Filosofia do Direito. 26. ed. Rio de Janeiro: Forense, 2019. 788530982805. Disponível em: https:// integrada.minhabiblioteca.com.br/\#/books/9788530982805/. Acesso em: 05 Mai 2020.

NADER, Paulo. Filosofia do direito. Rio de Janeiro: Forense, 2000.

PAUPÉRIO, Artur Machado. Introdução ao estudo direito. 2.ed. Rio de Janeiro: Forense, 1992.

PEDRO, Ana Paula. Ética, moral, axiologia e valores: confusões e ambiguidades em torno de um conceito comum. In: Kriterion: Revista de Filosofia, v. 55, n. 130, 2014.

PEREIRA, Rosane Maria Batista. O sistema ético-filosófico dos valores de Max Scheler. Porto Alegre: Est. Edições, 2000 .

PERLINGIERI, Pietro. La personsalità umana nell'orfinamento giuridico. Napoli: Edizioni Scientifiche Italiane, 1972.

PLATÃO. A República. São Paulo: Editora Scipione, 2002.

REALE, Miguel. Experiência e cultura. Campinas: Bookseller, 2000

REALE, Miguel. Filosofia do Direito. 9. ed. São Paulo: Saraiva, 1982

REALE, Miguel. Filosofia do Direito. 20.ed. São Paulo: Saraiva, 2002. 
REALE, Miguel. Lições Preliminares de Direito. São Paulo: Saraiva, 2002.

RIBEIRO, J. C. A ética como fator de resistência no jornalismo. In: Revista Brasileira de Ciências da Comunicação, v. XXIII, n. 2, p. 137-141 jul./dez. 2000.

SALGADO, Joaquim Carlos. Prefácio in: BROCHADO, Mariá. Direito e ética: a eticidade do fenômeno jurídico. São Paulo: Landy, 2006.

SARLET, Ingo Wolfgang. As dimensões da dignidade da pessoa humana: construindo uma compreensão jurídico-constitucional necessária e possível. Revista Brasileira de Direito Constitucional, n. 9, p. 361-388, jan./jun. 2007. Disponível em: http://www.esdc.com.br/seer/index.php/rbdc/article/view/137/131S. Acesso em: 25 nov 2019.

SCHELER, MAX, Le Formalisme en Étique, et L'Étique Materiale des Valeurs. 7.ed. Paris: Gallimard, 1955.

SCHELER, MAX, On Feeling, Knowing, and Valuing. Chicago: London Press, 1992.

SZANIAWSKI, Elimar. Direitos de personalidade e sua tutela. São Paulo: Revista dos Tribunais, 2005.

VALADIER, PAUL, A Anarquia dos Valores. Lisboa: Piaget, 1999.

VASCONCELOS, Arnaldo. Teoria da norma jurídica. 6 ed. São Paulo: Malheiros Editores, 2006.

VÁZQUEZ, A. S. Ética. Trad. João Dell'Anna. 7. ed. Rio de Janeiro: Civilização Brasileira, 1984.

Recebido/Received: 26.08.2019.

Aprovado/Approved: 26.07.2020. 